\title{
A new Neotropical genus of the family Cunaxidae (Acari: Prostigmata: Bdelloidea)
}

\author{
JACOB DEN HEYER ${ }^{1} \&$ TATIANE MARIE MARTINS GOMES DE CASTRO ${ }^{2}$ \\ ${ }^{1}$ Setor de Zoologia, Departamento de Entomologia, Fitopatologia e Zoologia Agrícola, Escola Superior de Agricultura "Luiz de \\ Queiroz”, Universidade de São Paulo, Piracicaba, São Paulo, Brasil, 13418-900.E-mail: jacob.den.heyer@gmail.com \\ South African Address: Department of Zoology and Entomology, University of the Free State, P.O.Box 339, Bloemfontein,9300,RSA. \\ Website:www.uovs.ac.za \\ ${ }^{2}$ Departamento de Fitossanidade, UNESP, Campus de Jaboticabal, São Paulo, Brasil, 14884-900. \\ E-mail: tatianemarie@yahoo.com.br
}

\begin{abstract}
A new Neotropical genus and its species, Allocunaxa heveae gen. et sp. nov., is described and figured. The generic features are provided. The subfamily Cunaxinae is discussed and a key to it is provided.
\end{abstract}

Key words: Bdelloidea, Neotropical, Cunaxinae, taxonomy, identification key

\section{Introduction}

Members of the family Cunaxidae are all free-living and predacious, forming an integral part of any kind of soil, plant and stored food ecosystem (Den Heyer \& Ryke 1966; Muma 1960, Gerson et al 2003). Their prey varies from nematodes, fungi, small arthropods, mainly mites and Collembola; some are even cannibalistic (Walter \& Kaplan 1991). Prior to 2007 only three species were reported from Brazil, namely Cunaxa denmarki $\{=$ Rubroscirus denmarki (Smiley 1992)\}, Scutascirus braziliensis Den Heyer and Dactyloscirus bison (Berlese) $\{=$ Armascirus bison (Berlese, 1888) $\}$. Faunistic studies of mites in Brazil from natural ecosystems (Arruda Filho \& Moraes 2002, Zacarias \& Moraes 2002, Castro \& Moraes 2007) and from plants of agricultural importance (Ferla \& Moraes 1998, Feres 2000, Feres et al. 2002, Ferla \& Moraes 2002, Barbosa et al. 2005) reported the Cunaxidae only at generic level. One of these studies reported a considerable diversity of this predatory group in the Atlantic Forest, one of the most important natural ecosystems of Brazil (Castro \& Moraes 2007). In the last quarter of 2007 the authors of this paper did a combined study of the Brazilian cunaxid fauna with the aim of describing as much new genera and species as possible. This is the fourth paper resulting from those studies in which a second new Brazilian genus mainly from rubber tree plantations is described.

\section{Material and methods}

Most specimens were sampled from rubber trees plantations, Hevea brasiliensis (Willd. Ex A. Juss.) Müll. Arg. (Euphorbiaceae), in the vicinity of Itiquira in the state of Mato Grosso, Brazil. One female was collected in Peru from Solanum melongena. The mites were mounted on glass slides using Hoyer's medium. An adapted version of Kethley's (1990) proposal for dorsal setal notation is used (Den Heyer \& Castro 2008); the appendage setal notation of Den Heyer (1981) is applied. All measurements $(\mu \mathrm{m})$ are given first in average 